\title{
PENGARUH WORK-FAMILY CONFLICT TERHADAP KOMITMEN ORGANISASI MELALUI STRES KERJA PADA TENAGA KESEHATAN RSU LATERSIA BINJAI
}

\author{
Nurul Hidayati ${ }^{1 \square}$, Muhammad Zarlis ${ }^{2}$, Yeni Absah $^{3}$ \\ ${ }^{1}$ Universitas Pasir Pengaraian \\ ${ }^{2,3}$ Universitas Sumatera Utara \\ Email : nurulhidayati@upp.ac.id
}

\begin{abstract}
Abstrak
Penelitian ini bertujuan untuk mengetahui dan menganalisis pengaruh work-family conflict terhadap komitmen organisasi melalui stres kerja. Populasi dan sampel dalam penelitian ini sebanyak 66 orang tenaga kesehatan RSU Latersia Binjai yang terdiri dari dokter umum, dokter spesialis, dokter gigi, apoteker, tenaga perawat dan bidan, dan tenaga kesehatan lain yang telah menikah. Metode analisis data menggunakan metode analisis jalur. Hasil penelitian menunjukkan secara parsial work-family conflict berpengaruh positif dan signifikan terhadap stres kerja, work-family conflict berpengaruh negatif dan signifikan terhadap komitmen organisasi dan stres kerja berpengaruh positif tidak signifikan terhadap komitmen organisasi. Pada analisis jalur didapatkan hasil work-family conflict berpengaruh langsung terhadap komitmen organisasi melalui stres kerja.
\end{abstract}

Kata kunci: Work-family conflict; stres kerja; komitmen organisasi

\section{EFFECT OF WORK-FAMILY CONFLICT ON ORGANIZATIONAL COMMITMENT THROUGH WORK STRESS ON RSU LATERSIA BINJAI HEALTH WORKERS}

\begin{abstract}
This study aims to determine and analyze the influence of work-family conflict on organizational commitment through work stress. In this study, the population and samples were 66 health workers of RSU Latersia Binjai, consisting of general practitioners, specialists, dentists, pharmacists, nurses and midwives, and other married health workers. The data analysis method uses the path analysis method. The results showed that partial work-family conflict positively and significantly affects work stress, work-family conflict negatively and significantly affects organizational commitment, and work stress has an insignificant positive effect on organizational commitment. In the analysis of the path obtained, the results of work-family conflict directly affect the organization's commitment through work stress.
\end{abstract}

Keywords: Work-family conflict; work stress; organizational commitment 


\section{PENDAHULUAN}

Dalam sebuah industri Rumah Sakit, tenaga kesehatan adalah sumber daya manusia yang memegang peranan penting. Suatu Rumah Sakit, dengan modal yang berlimpah disertai dengan teknologi yang canggih tidak akan bisa maju tanpa dijalankan oleh tenaga kesehatan yang berkualitas dan memiliki komitmen yang kuat dalam menjalankan setiap tugasnya.Komitmen organisasi tenaga kesehatan merupakan salah satu kunci yang turut menentukan berhasil atau tidaknya sebuah Rumah Sakit untuk mencapai tujuan. Tenaga kesehatan yang memiliki komitmen pada organisasi biasanya menunjukkan sikap kerja yang penuh perhatian terhadap tugasnya, memiliki tanggung jawab untuk melaksanakan tugas-tugas serta sangat loyal terhadap intansi tempatnya bekerja. Adanya komitmen organisasi yang tinggi pada tenaga kesehatan akan membuat mereka terhindar dari perilaku-perilaku keorganisasian yang negatif misalnya mangkir, pindah kerja ke Rumah Sakit lain, meninggalkan jam kerja dan lain sebagainya. Menurut Kaswan (2012), komitmen organisasi merupakan ukuran kesediaan karyawan bertahan dengan sebuah perusahaan di waktu yang akan datang. Sedangkan menurut Robbins dan Judge (2015), komitmen organisasi adalah tingkat dimana seorang pekerja mengidentifikasi sebuah organisasi, tujuan dan harapannya untuk tetap menjadi anggota.

Dalam menjalankan pekerjaan, seringkali para tenaga kesehatan menghadapi banyak tuntutan pekerjaan. Tuntutan pekerjaan yang tinggi tentunya memberikan dampak bagi kehidupan pribadi tenaga kesehatan yang bersangkutan. Bagi tenaga kesehatan yang telah berkeluarga, tuntutan pekerjaan yang tinggi tersebut tentunya dapat berdampak pada terabaikannya tugas yang harus dilakukan bagi keluarga yang dapat memicu munculnya konflik dalam keluarga. Konflik antara pekerjaan dan keluarga dapat terjadi baik pada wanita maupun pria. Menurut Martins et al., dalam Amelia (2010), work-family conflict adalah suatu keadaan yang terjadi ketika pekerjaan seseorang mempengaruhi atau mengganggu kehidupan keluarganya. Stres dapat diartikan sebagai sesuatu yang membuat kita mengalami tekanan mental atau beban kehidupan, suatu kekuatan yang mendesak atau mencekam, mengganggu keseimbangan karena masalah atau tuntutan penyesuaian diri.RSU Latersia Binjai adalah salah satu rumah sakit umum swasta yang berada di kota Binjai, dan satu-satunya Rumah Sakit Umum yang berada di Kecamatan Binjai Timur, berdiri di atas lahan seluas 29 x $146 \mathrm{~m}^{2}$. RSU Latersia Binjai dimulai dari Klinik Umum yang didirikan oleh dr. Robinson Sembiring pada 19 Juni 2004 dan sejak 13 Maret 2012 Kementrian Kesehatan Republik Indonesia menetapkan RSU Latersia Binjai sebagai Rumah Sakit Tipe C.Salah satu bentuk komitmen organisasi para tenaga kesehatan dapat dilihat dari loyalitas tenaga kesehatan untuk bertahan dan menjadi bagian dari rumah sakit tempatnya bekerja. Penulis melakukan pra survey terhadap 20 orang tenaga kesehatan yang sebagian besar adalah perawat dan bidan RSU Latersia Binjai terkait komitmen organisasi dengan pertanyaan apakah responden bersedia menerima jika ada tawaran pekerjaan di tempat lain. Dari 20 orang responden, 11 orang responden atau sebanyak 55\% menjawab bersedia. Para tenaga kesehatan yang masih berusia muda seperti perawat, bidan, dan dokter muda masih berupaya mencari tempat kerja yang lebih baik dari segi pemberian upah, ataupun ingin mencari pengalaman kerja di Rumah Sakit lain yang lebih besar (wawancara dengan bidan dan dokter umum).Para tenaga kesehatan yang sebagian adalah wanita yang telah menikah juga kerap menghadapi work-family conflict. Konflik ini dialami para tenaga kesehatan dikarenakan adanya benturan antara peran dirinya sebagai seorang tenaga kesehatan dan seorang istri sekaligus ibu dari anak-anaknya. Tuntutan peran sebagai tenaga kesehatan menuntutnya bekerja secara professional. Bagi perawat, bidan, dan dokter jaga harus bersedia bekerja pada berbagai shift yang berubah-ubah dan terkadang harus meninggalkan keluarga saat harus mengikuti pelatihan. Di sisi lain, ia adalah seorang istri yang harus melayani suami serta seorang ibu yang selalu diinginkan kehadirannya oleh anak-anak 
di rumah. Para tenaga kesehatan harus rela berkorban meninggalkan keluarga saat bertugas walau kadang menerima keluhan keluarga saat menjalankan shift malam. Selain itu, keletihan yang dialami di tempat kerja kerap terbawa ke rumah hingga mempengaruhi e mosi saat di rumah (wawancara dengan kepala ruangan dan perawat).

Banyaknya beban dan tekanan kerja seringkali membuat para tenaga kesehatan mengalami kelelahan dan berujung stres. Menurut Word Health Organization (WHO) 2011, beberapa negara di Asia Tenggara termasuk Indonesia, ditemukan fakta perawat yang bekerja di rumah sakit menjalani peningkatan beban kerja dan masih mengalami kekurangan jumlah perawat. Word Health Organization (WHO) menyatakan stres merupakan epidemi yang menyebar keseluruh dunia. Laporan PBB menjuluki stres kerja sebagai penyakit abad 20. Sebanyak 90\% dari pelayanan kesehatan di rumah sakit adalah pelayanan keperawatan, dari beberapa penelitian dikemukakan bahwa stres kerja merupakan hal lazim bagi perawat (Kalendesang, dkk 2017).

Dalam penelitian yang dilakukan oleh Nart dan Batur (2014), Jamadin, et al.,(2015) Sihaloho (2016), dan Agustina dan I Gde (2018) ditemukan bahwa karyawan, dalam hal ini tenaga kesehatan yang mengalami work-family conflict cenderung akan mengalami stres kerja. Work-family conflict dapat memberikan pengaruh negatif terhadap komitmen organisasi (Puspitasari, 2012; Nart dan Batur, 2014; Malik, et al., 2015; Sihaloho, 2016; Isnaini, 2018). Sedangkan menurut penelitian yang dilakukan oleh Lu, et al. (2009) tidak menemukan korelasi negatif yang signifikan dari work-family conflict dengan kepuasan kerja, komitmen organisasi, dan kepuasan karir. Penelitian yang dilakukan Rantika dan Sunjoyo (2011) juga tidak menemukan adanya pengaruh negatif antara work interfering with the family (WIF) dan komitmen organisasional serta tidak ada pengaruh negatif antara family interfering with the work (FIW) dan komitmen organisasional.

Adapun tujuan penelitian ini adalah:

1. Untuk menganalisis pengaruh work-family conflict terhadap stres kerja pada tenaga kesehatan RSU Latersia Binjai.

2. Untuk menganalisis pengaruh work-family conflict terhadap komitmen organisasi pada tenaga kesehatan RSU Latersia Binjai.

3. Untuk menganalisis pengaruh stres kerja terhadap komitmen organisasi pada tenaga kesehatan RSU Latersia Binjai.

4. Untuk menganalisis pengaruh work-family conflict terhadap komitmen organisasi melalui stres kerja pada tenaga kesehatan RSU Latersia Binjai.

Menurut Greenhaus dan Beutell (1985) dalam Sihaloho (2016), work-family conflict memiliki tiga bentuk:

1. Konflik karena waktu (time-based conflict), adalah banyaknya waktu yang dibutuhkan dalam memenuhi kebutuhan salah satu peran (pekerja atau keluarga) sehingga menyebabkan seseorang mengalami kesulitan dalam memenuhi kebutuhan peran lainnya.

2. Strain-based conflict merupakan banyaknya tekanan yang timbul dalam melakukan salah satu peran (pekerja/keluarga) sehingga membuat seeorang mengalami kesulitan memenuhi peran lainnya.

3. Behavior-based conflict yaitu adanya perilaku secara khusus yang dibutuhkan oleh salah satu peran (pekerja/keluarga) sehingga membuat seseorang mengalami kesulitan dalam memenuhi kebutuhan peran lainnya.

Menurut Robbins dan Judge (2015), bahwa terdapat tiga kategori dari sumber stres yang potensial yaitu faktor lingkungan, faktor organisasi, dan faktor individu. Stres diawali adanya sumber-sumber atau faktor penyebab yang dominan. Menurut Robbins, gelaja dari stres dapat dikelompokkan menjadi tiga kategori, yaitu: 
1. Gejala fisik

Gejala fisik atau fisiologis adalah gejala awal yang dapat diamati, terutama pada penelitian medis dan ilmu kesehatan. Stres cenderung berakibat pada perubahan metabolisme tubuh, meningkatnya detak jantung dan pernafasan, peningkatan tekanan darah, timbulnya sakit kepala, serta yang lebih berat lagi terjadinya serangan jantung.

2. Gejala Psikologis

Dari segi psikologis, stres dapat menyebabkan ketidakpuasan. Hal itu merupakan efek psikologis yang paling sederhana dan paling jelas. Namun bisa saja muncul keadaan psikologis lainnya, misalnya ketegangan, kecemasan, mudah marah, kebosanan, suka menunda-nunda. Bukti menunjukkan bahwa ketika orang ditempatkan dalam pekerjaan dengan tuntutan yang banyak dan saling bertentangan atau dimana ada ketidakjelasan tugas, wewenang dan tangggung jawab pemegang jabatan, maka stres maupun ketidakpuasan akan meningkat.

3. Gejala Perilaku

Gejala stres yang berkaitan dengan perilaku meliputi perubahan dalam tingkat produktivitas, absensi, kemangkiran dan tingkat keluarnya karyawan juga perubahan dalam kebiasaan makan, merokok dan konsumsi alkohol, bicara cepat, gelisah dan gangguan tidur.

Menurut Robbins dan Judge (2015), komitmen organisasi adalah tingkat dimana seorang pekerja mengidentifikasi sebuah organisasi, tujuan dan harapannya untuk tetap menjadi anggota. Sedangkan menurut Kaswan (2012), komitmen organisasi merupakan ukuran kesediaan karyawan bertahan dengan sebuah perusahaan di waktu yang akan datang. Menurut Mayer dan Allen dalam Kaswan (2012), komitmen organisasi terdiri atas tiga dimensi yaitu:

1. Komitmen Afektif

Menunjukkan kuatnya keinginan emosional karyawan untuk beradaptasi dengan nilainilai yang ada agar tujuan dan keinginannya untuk tetap di organisasi dapat terwujud. Komitmen afektif dapat timbul pada diri seseorang karyawan dikarenakan adanya: karakteristik individu, karakteristik struktur organisasi, signifikansi tugas, berbagai keahlian, umpan balik dari pimpinan dan keterlibatan dalam manajemen. Umur dan lama masa kerja di organisasi sangat berhubungan positif dengan komitmen afektif. Karyawan yang memiliki komitmen afektif akan cenderung untuk tetap dalam suatu organisasi karena mereka mempercayai sepenuhnya misi yang dijalankan oleh organisasi.

2. Komitmen Kelanjutan

Merupakan komitmen yang didasari atas kekhawatiran seseorang terhadap kehilangan suatu yang telah diperoleh selama ini dalam organisasi, seperti: gaji, fasilitas dan yang lainnya. Hal-hal yang menyebabkan adanya komitmen kelanjutan, antara lain adalah umur, jabatan dan berbagai fasilitas serta berbagai tunjangan yang diperoleh. Komitmen ini akan menurun jika terjadi pengurangan terhadap berbagai fasilitas dan kesejahteraan yang diperoleh karyawan.

3. Komitmen Normatif

Menunjukkan tanggung jawab moral karyawan untuk tetap tinggal dalam organisasi. Penyebab timbulnya komitmen ini adalah tuntutan sosial yang merupakan hasil pengalaman seseorang dalam berinteraksi dengan sesama atau munculnya kepatuhan yang permanen terhadap seorang panutan atau pemilik organisasi dikarenakan balas jasa, respek sosial, budaya atau agama. Individu dengan komitmen normatif yang tinggi akan tetap bertahan dalam organisasi karena merasa adanya suatu kewajiban atau tugas.

Berdasarkan latar belakang dan landasan teori yang telah dikemukaan, maka kerangka konseptual dalam penelitian ini adalah sebagai berikut: 


\section{METODE PENELITIAN}

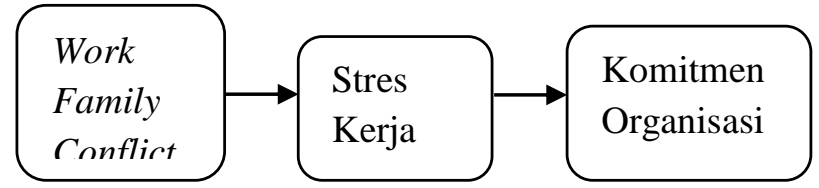

Gambar 1

Kerangka Konseptual

Jenis penelitian ini adalah deskriptif kausal. Populasi dalam penelitian ini adalah seluruh tenaga kesehatan RSU Latersia Binjai yang terdiri dari dokter umum, dokter spesialis, dokter gigi, apoteker, tenaga perawat, bidan, tenaga laboraturium, ahli gizi, radiologi, dan farmasi yang telah menikah berjumlah 66 orang. Penelitian ini menggunakan metode sensus yaitu seluruh populasi menjadi sampel penelitian. Jenis dan sumber data dalam penelitian ini adalah data primer dan data sekunder. Teknik pengumpulan data yang digunakan berupa observasi, wawancara, kuesioner, dan studi dokumentasi.

Variabel bebas dalam penelitian ini work-family conflict (X1), variabel terikat yaitu stres kerja (Y1) dan komitmen organisasi (Y2). Uji keandalan instrument meliputi uji validitas dan uji realibilitas, uji asumsi klasik meliputi uji normalitas, uji multikolonieritas dan uji heteroskedastisitas. Metode yang digunakan untuk analisis data adalah peralatan analisis jalur menggunakan program SPSS.

\section{HASIL DAN PEMBAHASAN}

Berdasarkan Uji Validitas diperoleh bahwa hasil pengujian instrumen variabel workfamily conflict pada item 2, 5, 7 dan 8 memiliki nilai $r_{\text {hitung }}<r_{\text {tabel }}(0,361)$. Dengan demikian item 2, 5, 7 dan 8 dihapus dalam penelitian sehingga total item pernyataan yang digunakan pada variabel work-family conflict hanya ada lima. Hasil pengujian instrumen variabel komitmen organisasi memiliki nilai $r_{\text {hitung }}>r_{\text {tabel }}(0,361)$. Dengan demikian seluruh instrumen pernyataan dari variabel komitmen organisasi adalah valid sehingga dapat digunakan di dalam penelitian. Hasil pengujian instrumen variabel stres kerja pada item 4 dan 7 memiliki nilai $\mathrm{r}_{\text {hitung }}<\mathrm{r}_{\text {tabel }}(0,361)$. Dengan demikian item 4 dan 7 dihapus dalam penelitian sehingga total item pernyataan yang digunakan pada variabel stres kerja hanya ada delapan. Dari Uji Reliabilitas diketahui nilai alpha untuk work-family conflict sebesar 0,731, komitmen organisasi sebesar 0,869, stres kerja sebesar 0,760 dan religiusitas sebesar 0,796. Dengan demikian dapat disimpulkan bahwa seluruh instrumen pernyataan bersifat reliable sehingga dapat digunakan dalam hasil penelitian.

Tabel 1

Hasil Analisis Regresi Sub-Struktural I

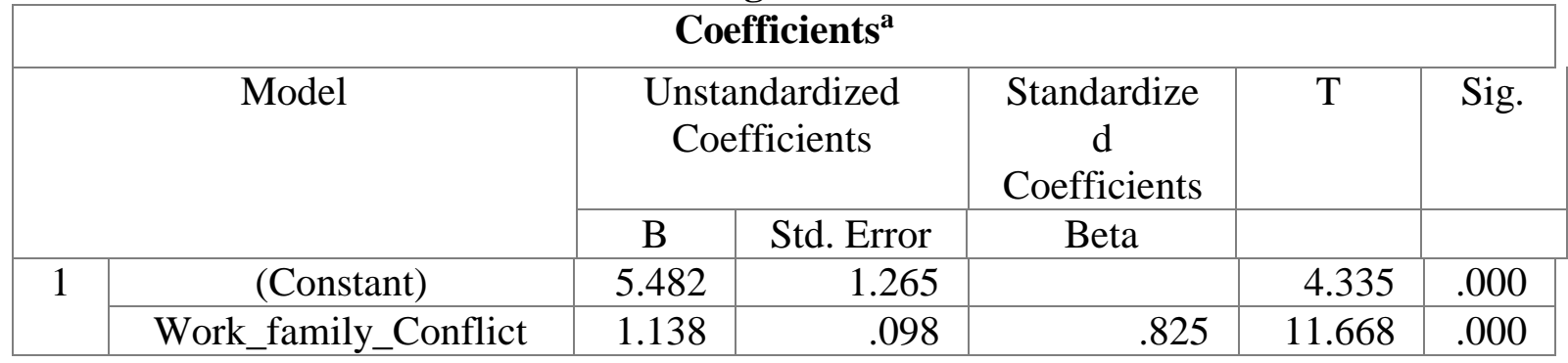

Berdasarkan Tabel 1 diperoleh model regresi Sub-Struktural I sebagai berikut: 


$$
\mathrm{Y}_{1}=5,482+1,138 \mathrm{X}
$$

Penjelasan nilai model di atas adalah sebagai berikut:

1. $\alpha=5,482$

Nilai konstanta $\alpha$ sebesar 5,482 menjelaskan bahwa apabila variabel work-family conflict bernilai nol, maka variabel stres kerja yang terbentuk sebesar 5,482

2. $\beta_{1}=1,138$

Konstanta $\beta_{1}$ bernilai 1,138 menjelaskan bahwa apabila variabel work-family conflict meningkat, maka variabel stres kerja akan meningkat.

Tabel 2

Hasil Analisis Regresi Sub-Struktural II Coefficients $^{\mathrm{a}}$

\begin{tabular}{|c|c|c|c|c|c|}
\hline \multirow[b]{2}{*}{ Model } & \multicolumn{2}{|c|}{$\begin{array}{c}\text { Unstandardized } \\
\text { Coefficients }\end{array}$} & \multirow[t]{2}{*}{$\begin{array}{c}\begin{array}{c}\text { Standardiz } \\
\text { ed } \\
\text { Coefficien } \\
\text { ts }\end{array} \\
\text { Beta }\end{array}$} & \multirow[b]{2}{*}{$\mathrm{T}$} & \multirow[b]{2}{*}{ Sig. } \\
\hline & B & Std. Error & & & \\
\hline $\begin{array}{c}\text { (Constant) } \\
\text { Work_family_Conflict } \\
\text { Stres_Kerja }\end{array}$ & $\begin{array}{c}38.586 \\
-.673 \\
.103\end{array}$ & $\begin{array}{l}1.870 \\
.224 \\
.163\end{array}$ & $\begin{array}{c}-.584 \\
.123\end{array}$ & $\begin{array}{c}20.630 \\
-2.999 \\
.632\end{array}$ & $\begin{array}{l}.000 \\
.004 \\
.529\end{array}$ \\
\hline
\end{tabular}

a. Dependent Variable: Komitmen_Organisasi

Sumber : Hasil Pengolahan SPSS versi 23

Berdasarkan Tabel 2 diperoleh model regresi Sub-Struktural II sebagai berikut:

$\mathrm{Y}_{2}=38,586-0,673 \mathrm{X}+0,103 \mathrm{Y}_{1}$

Penjelasan nilai model di atas adalah sebagai berikut:

1. $\alpha=38,586$

Nilai konstanta $\alpha$ sebesar 38,586 menjelaskan bahwa apabila variabel work-family conflict dan stres kerja bernilai nol, maka variabel komitmen organsasi yang terbentuk sebesar 38,586.

2. $\beta_{1}=-0,673$

Konstanta $\beta_{1}$ bernilai $-0,673$ menjelaskan bahwa apabila variabel work-family conflict meningkat, maka variabel komitmen organisasi akan menurun.

3. $\beta_{1}=0,103$

Konstanta $\beta_{1}$ bernilai 0,103 menjelaskan bahwa apabila variabel stres kerja meningkat, maka variabel komitmen organisasi akan meningkat.

Untuk menjawab hipotesis terkait dengan pengaruh variabel bebas terhadap variabel terikat melalui variabel intervening diperoleh hasil sebagai berikut:

1. Pengaruh Langsung

a. Pengaruh work-family conflict $(\mathrm{X})$ terhadap komitmen organisasi $\left(\mathrm{Y}_{2}\right)$

$\mathrm{X} \square \mathrm{Y}_{2}=\rho \mathrm{Y}_{2} \mathrm{X}=-0,584$ dengan sig.0,004

b. Pengaruh work-family conflict $(\mathrm{X})$ terhadap stres kerja $\left(\mathrm{Y}_{1}\right)$ 
$\mathrm{X} \square \mathrm{Y}_{1}=\rho \mathrm{Y}_{1} \mathrm{X}=0,825$

dengan sig. 0,000

c. Pengaruh stres kerja $\left(\mathrm{Y}_{1}\right)$ terhadap komitmen organisasi $\left(\mathrm{Y}_{2}\right)$

$\mathrm{Y}_{1} \square \mathrm{Y}_{2}=\rho \mathrm{Y}_{2} \mathrm{Y}_{1}=0,123$

dengan sig.0,529

2. Pengaruh Tidak Langsung

Pengaruh work-family conflict $(\mathrm{X})$ terhadap komitmen organisasi $\left(\mathrm{Y}_{2}\right)$ melalui stres $\operatorname{kerja}\left(\mathrm{Y}_{1}\right)$

$\mathrm{X} \square \mathrm{Y}_{1} \square \mathrm{Y}_{2}=\rho \mathrm{Y}_{1} \mathrm{X} * \rho \mathrm{Y}_{2} \mathrm{Y}_{1}=(0,825)(0,123)=0,101$

Tabel 3

Hasil Uji Intervening

\begin{tabular}{|c|c|r|r|r|c|}
\hline \multirow{2}{*}{ No } & \multirow{2}{*}{ Variabel } & \multicolumn{2}{|c|}{ Direct } & Indirect & Ket \\
\cline { 3 - 6 } & Stres Kerja & $\begin{array}{c}\text { Komitmen } \\
\text { Organisasi }\end{array}$ & \\
\hline 1 & $\begin{array}{c}\text { Work-Family } \\
\text { Conflict }\end{array}$ & $0,825^{* * *}$ & $-0,584^{* * *}$ & 0,101 & $\begin{array}{c}\text { Tidak } \\
\text { Intervening }\end{array}$ \\
\hline 2 & Stres Kerja & - & 0,123 & & \\
\hline
\end{tabular}

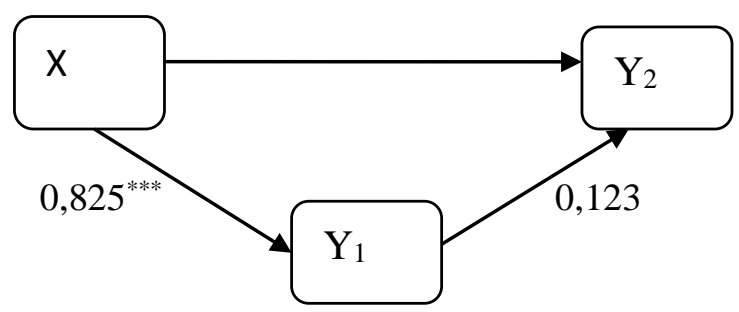

\section{Gambar 2 Model Analisis Jalur}

Hasil penelitian menunjukkan bahwa stres kerja tidak berperan sebagai variabel intervening pada penelitian ini.

Tabel 4

Hasil Uji Determinasi

Model Summary ${ }^{b}$

\begin{tabular}{|c|r|r|r|r|}
\hline Model & R & R Square & $\begin{array}{c}\text { Adjusted R } \\
\text { Square }\end{array}$ & $\begin{array}{l}\text { Std. Error of } \\
\text { the Estimate }\end{array}$ \\
\hline 1 & $.487^{\mathrm{a}}$ & .237 & .213 & 5.6551 \\
\hline
\end{tabular}

a. Predictors: (Constant), Stres_Kerja, Work_family_Conflict

b. Dependent Variable: Komitmen_Organisasi

Sumber : Hasil Pengolahan SPSS versi 23

Berdasarkan Tabel 4, nilai koefisien korelasi berganda (Adjusted $R$ Square) sebesar 0,213 . Hal tersebut menunjukkan bahwa $21,3 \%$ komitmen organisasi dapat dijelaskan oleh stres kerja dan work-family conflict, sedangkan sisanya sebesar 78,7\% dijelaskan oleh faktorfaktor lain yang tidak diteliti dalam penelitian ini seperti kepemimpinan, budaya organisasi, atau kompensasi. 


\section{Work-Family Conflict Berpengaruh Positif dan Signifikan Terhadap Stres Kerja}

Berdasarkan penelitian diperoleh hasil yang menyatakan bahwa work-family conflict berpengaruh positif dan signifikan terhadap stres kerja. Hal ini berarti konflik pekerjaankeluarga akan berdampak pada stres kerja. Semakin banyak masalah dalam rumah tangga yang memicu konflik akan meningkatkan stres kerja pada tenaga kesehatan di rumah sakit. Sebaliknya, semakin kecil konflik pekerjaan-keluarga yang dialami para tenaga kesehatan maka akan mengurangi stres kerja para tenaga kesehatan yang bekerja di rumah sakit.

Sebanyak 79\% dari responden dalam penelitian ini adalah wanita. Diketahui bahwa wanita adalah makhluk yang lebih mengedepankan emosi, Berdasarkan hasil dari beberapa studi juga diketahui bahwa wanita cenderung lebih mudah mengalami stres ketimbang pria karena perbedaan hormon dan genetik yang dimiliki wanita dan pria memiliki perbedaan. Tuntutan pekerjaan yang menjadikan wanita menjalani beberapa peran juga akan memicu stres. Dalam keluarga di budaya Timur, wanita memiliki peran yang sangat penting yaitu sebagai seorang istri yang melayani kebutuhan suami dan seorang ibu yang mengatur keperluan seluruh anggota keluarga terutama dalam pengasuhan anak-anak. Wanita pekerja harus mampu membagi waktu dan perhatian antara keluarga dan pekerjaan. Di saat kedua peran membutuhkan dirinya di waktu yang sama, ia harus mampu memilih dan membuat skala prioritas. Karena itu, peran dan dukungan keluarga besar menjadi sangat penting. Berdasarkan hasil jawaban responden, secara umum responden tidak mengalami work-family conflict dan stres kerja. Kemampuan wanita membagi peran dengan baik bisa menghindarkan mereka dari work-family conflict. Kemampuan mengelola konflik dengan baik juga mengakibatkan seorang wanita yang mengalami konflik cenderung tidak mengalami stres kerja.

Usia dan usia pernikahan juga menjadi faktor tenaga kesehatan yang mengalami workfamily conflict mengalami stres kerja. Sebagian besar responden dalam penelitian ini masih berusia muda. Sebanyak 51\% responden berusia 26-30 tahun dengan usia pernikahan yang paling dominan antara 1-5 tahun sebanyak 62\% responden. Usia 26-30 tahun masuk dalam kategori dewasa awal di mana belum masuk dalam kategori usia yang cukup matang. Di usia tersebut umumnya seseorang masih mengedepankan emosi dan ambisi, keras pada prinsip dan ideologi. Di usia pernikahan 1-5 tahun, umumnya seseorang masih melalui masa-masa lebih mengenal pasangan dan keluarga besar pasangan. Maka di usia muda dan usia pernikahan yang masih cenderung muda, setiap pasangan umumnya akan menjumpai beberapa konflik dalam kehidupan awal pernikahan. Konflik dalam keluarga bisa terjadi karena beberapa sebab, salah satunya adalah konflik peran yang disebabkan oleh tidak seimbangnya peran yang dijalani oleh suami atau istri dalam kehidupan pekerjaan dan keluarga. Namun, pasangan muda biasanya juga masih memiliki komitmen yang kuat dengan para pasangan sehingga kemampuan mengelola work-family conflict bagi pasangan muda akan menghindarkan mereka dari stres kerja.

Sebagai tenaga kesehatan yang telah bersumpah untuk profesional dalam bekerja yaitu dengan mengedepankan kepentingan pasien, maka mereka dituntut untuk memahami pentingnya keberadaan tenaga kesehatan dalam menangani pasien dalam kondisi sesulit apapun. Tuntutan profesi tenaga kesehatan sebaiknya juga diketahui oleh pihak keluarga besar tenaga kesehatan tersebut. Dalam penelitian ini misalnya, responden yang paling banyak adalah tenaga perawat dan bidan yang memiliki shift kerja yang senantiasa berubah dari waktu ke waktu. Demikian juga pada profesi dokter spesialis yang harus siap melakukan operasi darurat yang bisa datang kapan saja hingga harus rela meninggalkan keluarga demi mengedepankan keselamatan pasien. Maka, pihak keluarga harus siap dengan kondisi ini agar terhindar dari konflik dalam keluarga yang bisa menimbulkan stres kerja bagi tenaga kesehatan apabila tidak dapat dikelola dengan baik. 
Lama bekerja para tenaga kesehatan juga bisa menjadi faktor penyebab work-family conflict berpengaruh terhadap stres kerja. Sebanyak $77 \%$ responden dari penelitian ini adalah tenaga kesehatan yang baru bekerja selama kurun waktu 1-5 tahun di RSU Latersia Binjai. Semakin lama seseorang bekerja sebagai tenaga kesehatan, umumnya akan semakin terbiasa menjalani profesi dengan mobilitas kerja yang tinggi dan tuntutan pekerjaan yang banyak. Sebaliknya, masa kerja yang masih singkat bisa jadi penyebab belum terbiasanya tenaga kesehatan menghadapi berbagai konflik yang timbul dalam pekerjaan dan keluarga hingga menyebabkan stres kerja. Karena itu, masa-masa awal bekerja sebagai tenaga kesehatan di suatu rumah sakit adalah masa-masa beradaptasi dalam bekerja dan mengelola konflik dalam pekerjaan. Dalam penelitian ini secara umum responden tidak mengalami stres kerja yang berarti. Ini artinya para tenaga kesehatan sudah cukup mampu beradaptasi di dunia kerja hingga mampu menghindari stres kerja.

Dari jawaban responden terkait work-family conflict, sebanyak $37,9 \%$ dari responden merasa kurang memiliki waktu bersama keluarga namun sebanyak 40,9\% merasa masih sangat memiliki waktu bersama keluarga. Berkurangnya waktu bersama keluarga bisa menyebabkan kurangnya interaksi bersama keluarga. Sebanyak 34,8\% dari responden menjawab letih sepulang kerja menyebabkan mereka kurang memiliki waktu untuk berinteraksi bersama keluarga, namun sebanyak 24,2 merasa tidak setuju dan 31,8 merasa sangat tidak setuju yang artinya walaupun para tenaga kesehatan merasa letih sepulang dari kerja namun mereka masih memiliki waktu untuk berinteraksi bersama keluarga. Interaksi yang baik dengan keluarga dapat menghindarkan renggangnya hubungan anggota keluarga yang dapat memicu konflik.

Konflik yang dialami seseorang tenaga kesehatan dapat meningkatkan stres kerja, semakin tinggi konflik yang dialami oleh tenaga kesehatan maka semakin tinggi pula stres kerjanya. Sebaliknya, semakin rendah konflik yang dialami maka akan semakin rendah stres kerjanya. Penelitian ini sesuai dengan hasil penelitian yang dilakukan oleh Sihaloho (2016); Nart dan Batur (2014), Jamadin et al (2015), Siahaan (2018), dan Rusmewahni, et al (2018) yang menyatakan bahwa work family to conflict berpengaruh positif dan signifikan terhadap stres kerja. Sedangkan hasil penelitian ini bertolak belakang dengan penelitian yang dilakukan oleh Agustina dan Gde (2018) yang menyatakan bahwa work family to conflict tidak berpengaruh signifikan terhadap stres kerja.

\section{Work-Family Conflict Berpengaruh Negatif dan Signifikan terhadap Komitmen Organisasi}

Berdasarkan penelitian diperoleh hasil yang menyatakan bahwa work-family conflict berpengaruh negatif dan signifikan terhadap komitmen organisasi. Hal ini berarti konflik yang terjadi dalam keluarga akan berdampak pada menurunnya komitmen organisasi. Semakin banyak masalah dalam rumah tangga yang memicu konflik akan menurunkan komitmen organisasi tenaga kesehatan. Sebaliknya, semakin sedikit konflik pekerjaan-keluarga yang dialami tenaga kesehatan maka akan meningkatkan komitmen organisasi para tenaga kesehatan tersebut.

Bila dibandingkan antara wanita dan pria dalam memprioritaskan kepentingan keluarga, maka wanita akan lebih mementingkan keluarga. Hal ini karena wanita memiliki peran utama dalam mengurus kebutuhan domestik rumah tangga terlebih dalam budaya Timur, sedangkan pria lebih banyak memenuhi kebutuhan keluarga dalam hal tanggung jawab sebagai pencari nafkah yang utama dengan bekerja. Wanita, walaupun memiliki kewajiban sebagai pekerja, masih harus menyempatkan diri mengurus kebutuhan anggota keluarga yang terdiri dari suami, anak-anak, dan diri pribadi. Kehadirannya sebagai ibu yang menjadi pengasuh utama bagi anak-anaknya juga tidak dapat digantikan oleh siapapun. Karena itu, saat mengalami work-family conflict umumnya para wanita akan memprioritaskan kepentingan 
keluarganya yang berimbas pada komitmen organisasi tempatnya bekerja. Semakin tinggi work-family conflict yang dialami akan menurunkan komitmen organisasi. Berdasarkan hasil jawaban responden, secara umum responden tidak mengalami work-family conflict, responden secara umum juga memiliki komitmen organisasi yang baik.

Pada tenaga kesehatan yang umumnya berusia muda dengan usia pernikahan yang juga masih muda, menjalani peran sebagai anggota keluarga dan tenaga kesehatan memerlukan adaptasi yang baik agar terhindar dari konflik. Hal ini mengingat tenaga kesehatan memiliki mobilitas kerja yang tinggi sehingga kerap meninggalkan keluarga. Namun, pada usia pernikahan yang masih muda, para pasangan umumnya juga akan lebih giat bekerja untuk dapat memenuhi kebutuhan keluarga yang baru dibangun. Karena itu, para tenaga kesehatan akan lebih berusaha menghindari work-family conflict untuk meningkatkan komitmen organisasi di tempat kerja.

Secara umum, responden dalam penelitian ini adalah tenaga kesehatan yang baru bekerja selama 1-5 tahun yaitu sebanyak $77 \%$. Sebagai tenaga kesehatan yang baru mulai bekerja di sebuah Rumah Sakit, umumnya para tenaga kesehatan tersebut akan melakukan pekerjaan dengan sebaik mungkin sebagai bagian dari penjajakan karir. Ini menjadikan mereka akan lebih komitmen terhadap rumah sakit tempat mereka bekerja.

Penelitian ini sesuai dengan hasil penelitian yang dilakukan oleh Sihaloho (2016); Puspitasari (2012); Isnaini (2018); Nart \& Batur (2014); Malik, et al (2015); Li, et al. (2013) dan Hatam (2016) yang menyatakan bahwa work-family conflict berpengaruh signifikan terhadap komitmen organisasi. Akan tetapi hasil penelitian ini bertolak belakang dengan penelitian yang dilakukan oleh Rantika \& Sunjoyo (2015) dan Nwuggballa (2016) yang menyatakan bahwa work-family conflict berpengaruh tidak signifikan terhadap komitmen organisasi.

\section{Stres Kerja Berpengaruh Positif Tidak Signifikan terhadap Komitmen Organisasi}

Berdasarkan penelitian diperoleh hasil yang menyatakan bahwa stres kerja berpengaruh positif dan tidak signifikan terhadap komitmen organisasi. Hal ini berarti stres kerja tidak menjadi pemicu menurunnya komitmen organisasi pada tenaga kesehatan di RSU Latersia Binjai.Pada penelitian ini didapatkan hasil bahwa rata-rata dari responden yang terdiri dari tenaga kesehatan RSU Latersia Binjai tidak mengalami stres kerja. Bila ada responden yang mengalami stres kerja maka masih dikategorikan stres kerja ringan. Secara umum responden tidak mengalami gejala dari stres kerja yaitu gejala fisik yang terdiri dari sakit kepala, tekanan darah naik, dan sakit lambung. Responden secara umum tidak mengalami gejala psikologis seperti gelisah, depresi, dan penurunan kepuasan kerja. Responden secara umum juga tidak mengalami gejala perilaku dari stres kerja seperti kinerja menurun, motivasi rendah, absensi, dan perpindahan.

Tidak berpengaruhnya stres kerja secara signifikan terhadap komitmen organisasi juga bisa disebakan karena tenaga kesehatan adalah profesi yang setiap hari mendapat tekanan kerja yang tinggi. Tenaga kesehatan telah terbiasa atau membiasakan diri menghadapi berbagai tekanan kerja di rumah sakit, menghadapi keluhan pasien yang beragam, hingga menghadapi berbagai kegagalan menyelamatkan nyawa pasien. Semua tekanan kerja yang melibatkan emosi sudah biasa dihadapi secara profesional sesuai dengan sumpah profesi. Karena itu, seberat apapun tekanan kerja di rumah sakit yang mengakibatkan stres kerja dapat diatasi karena harus komitmen menyelamatkan nyawa pasien, juga agar dapat melanjutkan kerja-kerja berikutnya yang telah menanti. Memilih profesi sebagai tenaga kesehatan harus sepaket dengan kesiapan mental menghadapi tekanan kerja yang datang dan pergi dengan cepat agar dapat menjaga komitmen. 
Chong dalam Khan (2014) menyatakan bahwa karyawan dengan komitmen organisasi yang tinggi akan senang berada di dalam organisasi. Salah satu penyebab tingginya komitmen oganisasi adalah rendahnya stres kerja. Tingkat stres kerja yang tinggi akan memicu karyawan untuk jenuh dalam bekerja dan lama kelamaan akan mencari pekerjaan lain yang lebih nyaman. Namun, tingkat stres tidak akan berpengaruh jika karyawan dapat mengendalikan diri atas sikapnya ditempat kerja. Kebutuhan akan pekerjaan juga menjadi pertimbangan untuk tetap bertahan dalam kondisi beban kerja yang rawan memicu stres. Hanya ada 9 unit Rumah Sakit di kota Binjai, dan RSU Latersia adalah satu-satunya Rumah Sakit yang berada di Kecamatan Binjai Timur. Alasan domisili menjadi pertimbangan bagi tenaga kesehatan yang telah berkeluarga terutama wanita untuk tetap komitmen dan bertahan di RSU Latersia Binjai.

Penelitian ini sesuai dengan penelitian yang dilakukan oleh Viktorius (2013) yang menunjukkan bahwa stres kerja tidak berpengaruh langsung secara signifikan terhadap komitmen organisasi. Penelitian tersebut dilakukan di RSUD dr. Soedarso Pontianak. Lazarus and Folkman dalam Viktorius (2013) menyatakan stres timbul akibat hubungan individu dengan lingkungannya yang dinilai individu melebihi sumber daya dan membahayakan kesehatan. Kemampuan individu mengatasi masalah, apakah stres terjadi atau terbentuk koping, tergantung cara menginterpretasikan atau mempersepsikan dan mengukur dengan kejadian lingkungan. Persepsi merupakan reaksi individu terhadap sumber stres potensial yang dapat menyebabkan stres. Penelitian ini bertolak belakang dengan hasil penelitian yang dilakukan oleh Sihaloho (2016) dan Nart \& Batur (2014) yang menunjukkan bahwa stres kerja berpengaruh negatif terhadap komitmen organisasi.

\section{Work-Family Conflict Berpengaruh Langsung terhadap Komitmen Organisasi melalui Stres Kerja}

Berdasarkan penelitian diperoleh hasil yang menyatakan bahwa secara langsung workfamily conflict berpengaruh negatif dan signifikan terhadap komitmen organisasi. Hal ini berarti tenaga kesehatan yang memiliki masalah dalam rumah tangga cenderung akan mempengaruhi komitmen pada pekerjaannya. Pada uji parsial diperoleh hasil bahwa stres kerja berpengaruh positif dan tidak signifikan terhadap komitmen organisasi tenaga kesehatan di RSU Latersia Binjai, maka stres kerja tidak berfungsi sebagai variabel intervening dalam penelitian ini.

Pada analisis jawaban responden terkait stres kerja rata-rata responden menjawab tidak setuju dengan nilai 2,36 yang menunjukkan secara umum responden tidak mengalami stres kerja yang berarti. Bila ada tenaga kesehatan yang mengalami stres kerja maka masih dalam kategori stres kerja ringan. Pekerjaan di rumah sakit adalah pekerjaan yang berhubungan dengan penyakit, nyawa, dan keselamatan pasien yang berpotensi meningkatkan stres, namun di sisi lain ada kewajiban moral setiap tenaga kesehatan terkait setiap kondisi pasien di rumah sakit yaitu untuk mengobati atau menyelamatkan nyawa si sakit. Ini sesuai dengan dimensi komitmen normatif yaitu adanya perasaaan wajib untuk tetap berada dalam organisasi karena memang harus begitu dan tindakan tersebut merupakan hal benar yang harus dilakukan. Ini sesuai dengan penelitian yang dilakukan oleh Viktorius (2013).

Dalam penelitian ini, work-family conflict berpengaruh langsung terhadap komitmen organisasi melalui stres kerja. Penelitian ini bertolak belakang dengan penelitian yang dilakukan oleh Sihaloho (2016), Siahaan (2016), dan Divara dan Agoes (2016) yang menunjukkan bahwa work-family conflict berpengaruh tidak langsung terhadap komitmen organisasi melalui stres kerja. Dengan kata lain, stres kerja dapat memediasi pengaruh workfamily conflict terhadap komitmen organisasi. 


\section{KESIMPULAN}

Berdasarkan hasil penelitian dan analisis data pada bab sebelumnya, maka diperoleh beberapa kesimpulan yaitu:

1. Work-family conflict berpengaruh positif dan signifikan terhadap stres kerja pada tenaga kesehatan RSU Latersia Binjai.

2. Work-family conflict berpengaruh negatif dan signifikan terhadap komitmen organisasi pada tenaga kesehatan RSU Latersia Binjai.

3. Stres kerja berpengaruh positif dan tidak signifikan terhadap komitmen organisasi pada tenaga kesehatan RSU Latersia Binjai.

4. Work-family conflict berpengaruh langsung terhadap komitmen organisasi melalui stres kerja pada tenaga kesehatan RSU Latersia Binjai.

Berdasarkan hasil penelitian dan pembahasan pada bab terdahulu, maka beberapa saran yang dijadikan tindak lanjut adalah sebagai berikut:

1. Untuk pihak manajemen RSU Latersia Binjai

a. Hendaknya tetap profesional dalam mengatur jam kerja para tenaga kesehatan, bila perlu mengadakan reward and punishment untuk memotivasi karyawan agar lebih disiplin.

b. Mengadakan rekrutmen tenaga kesehatan terutama untuk tenaga perawat dan bidan agar pembagian kerja lebih merata mengingat bertambahnya jumlah pasien dikarenakan program BPJS Kesehatan.

c. Menyediakan layanan konseling kepada para tenaga kesehatan yang sedang mengalami konflik.

d. Mengadakan pelatihan dan pengembangan terhadap tenaga kesehatan sebagai sarana memotivasi dan menanamkan nilai-nilai budaya organisasi rumah sakit agar setiap tenaga kesehatan merasa lebih bangga dan berbahagia menghabiskan sisa karir mereka di rumah sakit ini.

e. Memenuhi semua kebutuhan para tenaga kesehatan dengan sistem kompensasi yang adil, serta memberikan bonus dan penghargaan bagi tenaga kesehatan yang berprestasi.

f. Memperhatikan kesehatan fisik dan psikis para tenaga kesehatan agar lebih profesional dan komitmen dalam melakukan semua pekerjaan.

g. Mengadakan visualisasi atau briefing kepada tenaga kesehatan sebelum melakukan pekerjaan untuk menambah motivasi dalam bekerja.

h. Menampung kritik dan saran dari para tenaga kesehatan sehingga apabila ada masalah dapat segera diatasi bersama.

i. Menjalin hubungan yang baik dengan para tenaga kesehatan, bisa dimulai dengan memperbaiki pola komunikasi atau dengan mengadakan kegiatan bersama seperti "family gathering" agar jumlah tenaga kesehatan yang pindah kerja semakin berkurang.

2. Untuk peneliti selanjutnya

a. Berdasarkan hasil uji determinasi, diperoleh hasil bahwa komitmen organisasi hanya dapat dijelaskan oleh stres kerja dan work-family conflict sebesar 21,3\%. Maka disarankan untuk peneliti selanjutnya dapat meneliti variabel lain yang dapat menjelaskan komitmen organisasi dengan lebih baik seperti kepemimpinan, budaya organisasi atau kompensasi. 
b. Terkait penelitian yang menggunakan variabel work-family conflict lebih baik difokuskan pada satu jenis kelamin agar lebih fokus dalam hal pembahasan.

\section{DAFTAR PUSTAKA}

Agustina, Reni dan I Gde Adnyana Sudibya. 2018. Pengaruh Work Family Conflict Terhadap Stres Kerja dan Kinerja Wanita Perawat di Rumah Sakit Umum Daerah Praya Lombok. E-Jurnal Ekonomi dan Bisnis Universitas Udayana 7.3 (2018):775-808.

Akintayo, D.I. 2010. Work-Family Role Conflict and Organizational Commitment among Industrial Workers in Nigeria. Journal of Psychology and Counseling.Vol. 2 No. 1.

Amelia, Anisah. 2010. Pengaruh Work-to-Family Conflict dan Family-to-Work Conflict Terhadap Kepuasan dalam Bekerja, Keinginan Pindah Tempat Kerjadan Kinerja Karyawan. Jurnal Ekonomi dan Bisnis.Vol. 4 No. 3.

Anafarta, Nilgun. 2011. The Relationship between Work-Family Conflict and Job Satisfaction: A Structural Equation Modeling (SEM) Approach. International Journal of Business and Management Vol. 6, No. 4.

Arikunto, Suharsimi. 2010. Manajemen Penelitian. Cetakan Kesebelas. Jakarta: Rineka Cipta. Carlson dan Kacmar. 2000. Work-Family Conflict in the Organization : Do life role Values make a Difference. Journal of management. 26 (5): 1031-1054

Farradinna, Syarifah. \& Halim, Fatimah Wati. 2016. The Consequences of work-family conflict, burnout and organizational commitment among women in Indonesia. Procedia - Social and Behavioral Sciences, 219: 241 - 247.

Ghozali, Imam. 2013. Aplikasi Analisis Multivariate dengan Program SPSS. Semarang: Badan Penerbit Universitas Diponegoro.

Greenhaus, J. H., G. A. Callanan, and V. M. Godshalk. 2000. Career Management, Third edition. United States of America: The Dryden Press

Hasibuan, SP. Melayu. 2014. Manajemen Sumber Daya Manusia. Edisi Revisi. Jakarta: Bumi Aksara.

Hatam, Nahid; Marzie Tajik Jalali; Mehrdad Askarian; Erfan Kharazmi. 2016. Relationship between Family-Work and Work-Family Conflict with Organizational Commitment and Desertion Intention among Nurses and Paramedical Staff at Hospitals. IJCBNM April 2016; Vol 4, No 2.

Kalendesang, Monique P, Hendro Bidjuni, Reginus T. Malara. 2017. Hubungan Konflik Peran Ganda Perawat Wanita Sebagai Care Giver Dengan Stres Kerja Di Ruangan Rawat Inap Rumah Sakit Jiwa Prof. Dr.V. L. Ratumbuysang Provinsi Sulawesi Utara. $e$ Journal Keperawatan (e-Kp) Volume 5 Nomor 1.

Kaswan. 2012. Manajemen Sumber Daya Manusia untuk Keunggulan Bersaing Organisasi. Edisi Pertama. CetakanPertama. Yogyakarta: GrahaIlmu. 
Li, Chaoping. Lu, Jiafang. \& Zhang, Yingying. 2013. Cross-Domain Effects of Work-Family Conflict on Organizational Commitment and Performance. Social Behavior And Personality, 41 (10): 1641-1653.

Lu, J.-F., Siu, O.-L., Spector, P. E., \& Shi, K. 2009. Antecedents and outcomes of a four fold taxonomy of work-family balance in Chinese employed parents. Journal of Occupational Health Psychology, 14, 182-192.

Luthans, F. 2008. Perilaku Organisasi. Edisi 10. Yogyakarta: Penerbit Andi.

Malik, Shoukat, Abdul Ghafoor Awan, Qurat-ul-Ain. 2015. Role of Work-Family Conflict on Organizational Effectiveness in The Institute of Southern Punjab- Pakistan. European Journal of Business and Management.Vol. 7 No. 1.

Mangkunegara, A.A. Prabu. 2007. Manajemen Sumber Daya Manusia Perusahaan. Cetakan Ketujuh. Bandung: Remaja Rosdakarya.

Mondy, R. Wayne. 2008. Manajemen Sumber Daya Manusia, Edisi Kesepuluh Jilid 1. Jakarta: Penerbit Erlangga.

Nwugballa, Emmanuel Agwu ARISI. 2016. Evaluating the Relationship between Work-Family Conflict and Organisational Commitment among Rural Women Health Workers in Ebonyi State, Nigeria. International Journal of Academic Research in Accounting, Finance and Management Sciences .Vol. 6, No. 3, July 2016, pp. 212-220 E-ISSN: 2225-8329, P-ISSN: 2308-0337

Puspitasari, Ayu. 2011. Pengaruh Konflik Pekerjaan-Keluarga terhadap Komitmen Organisasi dengan Kepuasan Kerja. Jurnal Ekonomi dan Kebijakan. Vol. 5 No.1

Rantika, Renny dan Sunjoyo. 2011. Pengaruh Konflik Kerja-Keluarga terhadap Komitmen Organisasional yang Dimediasi oleh Kepuasan Kerja pada Profesi Perawat di Rumah Sakit Umum Daerah (RSUD) Dr. Moewardi Surakarta. Jurnal Manajemen Teori dan Terapan| Tahun 4, No. 2, Agustus 2011.

Richardus, Chandra Wirakristama. 2011. Analisis Konflik Peran (Work-Family Conflict) terhadap Kinerja Karyawan Wanita pada PT. NyonyaMeneer Semarang dengan Stres Kerja Sebagai Variabel Intervening. Skripsi. Fakultas Ekonomi dan Bisnis Universitas Diponegoro. Semarang.

Robbins, Stephen P. 2003. Prinsip-prinsip Perilaku Organisasi. Jakarta: Penerbit Erlangga.

Robbins, Stephen. P; dan Judge Timothy. A. 2015. Perilaku Organisasi. Edisi Enam Belas. Jakarta: Salemba Empat.

Rohayati, Dwi. 2014. Pengaruh Kompensasi, Motivasi Dan Religiusitas Terhadap Kinerja Karyawan Pada BMT Di Kota Salatiga Dan Kabupaten Semarang. Skripsi. Jurusan Syariah Dan Ekonomi Islam Sekolah Tinggi Agama Islam Negeri (STAIN) Salatiga.

Sihaloho, Ronal Donra. 2016. Pengaruh Work-to-Family Conflict dan Stres Kerja terhadap Komitmen Organisasi dengan Kepuasan Kerja sebagai Variabel Intervening pada PT Pelabuhan Indonesia I (Persero) Medan. Tesis. Magister Ilmu Manajemen Universitas Sumatera Utara. 
Sinulingga, Sukaria. 2016. Metode Penelitian Bisnis. Sumatera Utara: USU Press.

Situmorang, Syafrizal Helmi, Iskandar Muda, Doli M. Ja'far Dalimunthe, Fadhli Fauzie Syarief. 2010. Analisis Data untuk Riset Riset Manajemen dan Bisnis. Medan: USU Press.

Sopiah. 2008. Perilaku Organisasional. Yogyakarta: CV Andi Offset

Sugiyono. 2013. Metode Penelitian Pendidikan. Bandung: Alfabeta. 